\title{
Using Information-Gap Decision Theory for Water Resources Planning Under Severe Uncertainty
}

\author{
Brett Korteling • Suraje Dessai • Zoran Kapelan
}

Received: 16 December 2011 / Accepted: 25 September 2012 /

Published online: 18 October 2012

(C) Springer Science+Business Media Dordrecht 2012

\begin{abstract}
Water resource managers are required to develop comprehensive water resources plans based on severely uncertain information of the effects of climate change on local hydrology and future socio-economic changes on localised demand. In England and Wales, current water resources planning methodologies include a headroom estimation process separate from water resource simulation modelling. This process quantifies uncertainty based on only one point of an assumed range of deviations from the expected climate and projected demand 25 years into the future. This paper utilises an integrated method based on Information-Gap decision theory to quantitatively assess the robustness of various supply side and demand side management options over a broad range of plausible futures. Findings show that beyond the uncertainty range explored with the headroom method, a preference reversal can occur, i.e. some management options that underperform at lower uncertainties, outperform at higher levels of uncertainty. This study also shows that when $50 \%$ or more of the population adopts demand side management, efficiency related measures and innovative options such as rainwater collection can perform equally well or better than some supply side options The additional use of Multi-Criteria Decision Analysis shifts the focus away from reservoir expansion options, that perform best in regards to water availability, to combined strategies that include innovative demand side management actions of rainwater collection and greywater reuse as well efficiency measures and additional regional transfers. This paper illustrates how an Information-Gap based approach can offer a comprehensive picture of
\end{abstract}

\footnotetext{
B. Korteling $(\bowtie)$

Geography, College of Life and Environmental Sciences, University of Exeter, Amory Building, Rennes Drive, Exeter EX4 4RJ, UK

e-mail: bak203@exeter.ac.uk
}

\section{S. Dessai}

Sustainability Research Institute and ESRC Centre for Climate Change Economics and Policy, School of Earth and Environment, University of Leeds, Leeds LS2 9JT, UK

e-mail: S.Dessai@leeds.ac.uk

\section{Z. Kapelan}

Engineering, College of Engineering, Mathematics and Physical Sciences, University of Exeter, Harrison Building, North Park Road, Exeter EX4 4QF, UK

e-mail: Z.Kapelan@exeter.ac.uk 
potential supply/demand futures and a rich variety of information to support adaptive management of water systems under severe uncertainty.

Keywords Water resources $\cdot$ Uncertainty $\cdot$ Climate change $\cdot$ Planning $\cdot$ Demand management $\cdot$ Info-Gap

\section{Introduction}

This paper introduces a new water resources planning methodology based on InformationGap (shortened to Info-Gap) decision theory. This approach includes the benefits of an integrated modelling framework (Collins and Ray 2009; Mayer and Muñoz-Hernandez 2009) and address the complexity of decision-making under severe uncertainty (Bates et al. 2008; Lempert and Schlesinger 2000; NRC 2009; US Climate Change Science Program 2009). The potential for severely different weather patterns associated with climate change coupled with uncertain socio-economic futures forces water managers to be prepared for not only challenging supply/demand situations that have occurred in the past, but also the potential for far worse conditions in the future. With climate change there is agreement on a general warming trend; but the extent of warming and when, and the resulting effects on localised systems that require adaptation decisions are not clear. This lack of knowledge can be considered a gap in the information required to make suitable decisions. Info-Gap decision theory (Ben-Haim 2001) offers a method to sample a wider range of uncertainty than with traditional methods, and as a result, evaluate the performance of various water resource management options under conditions of severe uncertainty.

This information on how different management interventions succeed over a range of futures makes it possible to be prepared to adapt should circumstance change from what is expected. Adaptive management is a decision making process that facilitates the prioritisation of management interventions based on level of necessity, along with the freedom to change these priorities over time (Lempert and Groves 2010; Ranger et al. 2010). When preparing an adaptive management plan, it's important to have a portfolio of different management actions that can respond to different system conditions. To place heavy investment in management options for a severe future without full evidence of its actuality would not be prudent and likewise, to not be prepared to shift management direction towards options that safeguard for severe conditions would not be responsible. The management options explored in this paper are not designed as adaptive portfolios, but are investigated as different options that could become part of an adaptive management plan.

Uncertainties are commonly explored with Monte Carlo simulations or other methods (see, e.g., Dessai and van der Sluijs 2011). However, there are many situations where there is not enough knowledge to be able to estimate a representative probability of occurrence, or to be confident that the tails of an assumed probability distribution will not exhibit unexpected skewness, or that the kurtosis of a distribution differs from the norm. These situations can be considered severely uncertain. In water resources management the tails of a distribution are important as they can represent unexpected droughts or increases in demand.

Current planning methodologies in England and Wales do not evaluate or compare how management options perform under severe uncertainty. The current approach of the basic and intermediate modelling framework for long-term water resources planning, as outlined in the Economics of Balancing Supply and Demand (EBSD) report (NERA 2002), assesses the ability of water resources management options to satisfy the supply/demand balance and the associated uncertainty within a defined ranged of uncertainty and in separate analytic 
operations in a non-integrated fashion. The water resources planning process is based on the concepts of level of service (defined as target service failure frequency) and headroom (safety margin between water supply available and the demand required). The uncertainties in supply and demand forecasts, represented by probability density functions (PDFs), are ultimately propagated to the headroom PDF. The selection of the optimal set of water resources management options (for a chosen level of service) is then driven by a cost minimisation optimisation subject to target headroom defined as a fixed percentile of the estimated headroom PDF. As a consequence, the target headroom uncertainty is bounded, i.e. the full range of possible futures is not explored. Other important aspects such as the environmental impact and carbon emissions of various management interventions are considered but not with as much emphasis as cost and level of service and again, only for a limited range of uncertainty. Adaptive management is not specifically made reference to as the standard approach is to select one optimum management regime to deal with one expected future and its accompanying expected range of headroom uncertainty.

This paper describes how an Info-Gap based approach evaluates the performance of management options under conditions of severe uncertainty in five sections. The background section (2) reviews the literature of uncertainty in water resources planning and briefly critiques the current approach. The methodology section (3) describes how uncertainty is characterised and quantified using an Info-Gap approach. The specifics of this application of Info-Gap decision theory are introduced in the case study section (4). An example of robustness and opportuness curves and the results of an additional Multi-Criteria Decision Analysis step are discussed in the results at the end of section 4. A conclusion section (5) emphasises the main benefits and limitations of using Info-Gap and future research directions.

\section{Background}

\subsection{Sources of Uncertainty in Water Resources Planning}

The practice of water resources planning has always recognised variable weather patterns and their accompanying change in hydrology and influence on dry season water demand. Previously these factors could be considered in terms of probabilities of return; a 1:40 year drought or a 1:10 winter storm, etc. However, since climate change has begun to show its effects on weather patterns and as a result, influenced a 'more than normal' change in local hydrology, the previously thought 'normal' frequency of events can no longer be taken for granted (Milly et al. 2008; Kiang et al. 2011). The accumulated knowledge of seasonal and yearly hydrological changes as expressed in probability distributions is a helpful background but an uncertain guide for the future.

In England and Wales, water resources management requires looking to the future for at least 25 years (Environment Agency 2008). Most water companies rely on stream gauge information to assess their available supply in terms of inflow from streams or rivers and recharge rates for groundwater aquifers to assess the pump-able yield for which they have abstraction rights. The effect of climate change necessitates a re-evaluation of historical data and a method to simulate future river flows and recharge rates, etc. as perturbed by new weather regimes. There is a cascade of modelled information to consider before a future value for daily inflow or groundwater yield can be ascertained (Jones 2000; New et al. 2007; Ranger et al. 2010; Wilby and Dessai 2010). The effects of future emission scenarios drive future global weather patterns represented by different Global Climate Models (GCMs); 
GCMs are downscaled by Regional Climate Models (RCMs); from RCM variables the effects on local hydrology are assessed by a variety of impact models. Each of these steps and the final assessment of different adaptive policy responses to address these impacts contain associated uncertainties (Wilby 2010). The current practice of the water industry in England and Wales to optimise under a set of expected circumstances is no longer enough to plan for a variable future (Hall et al. 2011).

The assignment of probabilities to climate change projections may offer a view of the future that is more approachable for probabilistic risk analysis and more easily interpreted through the lens of risk management (cf. McIntyre et al. 2003). This probabilistic presentation can easily become a misrepresentation, as these probability distributions are heavily influenced by choice of GCM (New et al. 2007) and the post-processing techniques employed to downscale to the local level (New et al. 2007; Lopez et al. 2006). There are also more subtle uncertain influences arising from the emission scenarios and impact model parameters (Wilby and Harris 2006; Dessai et al. 2009). To some extent the bias of GCM choice can be addressed by taking an ensemble approach (Lopez et al. 2009; Manning et al. 2009), but a proper representation of the probability of impacts can only be achieved by a thorough end-to-end analysis (New et al. 2007), and an understanding of the downscaling techniques used, specific to the impact that needs to be explored (Lopez et al. 2006). The UK Climate Projections 2009 (UKCP09; Murphy et al. 2009) provide a probabilistic range of expected climate futures, but their applicability to water resources planning is still being explored and debated (e.g., UKWIR 2009; Darch et al. 2011; Arnell 2011; HM Government 2012).

The future supply of water is not the only aspect of water resources planning in question. Future demand is also difficult to predict. The call for sustainability, new building requirements and more efficient water use, has motivated water companies to develop different initiatives to lessen consumption, but how much less people are willing and able to live with, and the success of different demand management initiatives is still in question (Arnell 1998; Arnell and Delaney 2006; Environment Agency 2001, 2004). For example, in the South West Water (SW Water) Water Resources Plan 2009, the cumulative range of uncertainty that results from all the uncertainties related to demand including demand-side meters, demand forecast, the effect of climate change on demand and the effect of demand side management is almost double the range attributed to an aggregation of the uncertainties associated with the supply side parameters (SW Water 2009).

\subsection{Characterising and Quantifying Uncertainty with the EBSD Approach}

Current long term water resources planning in the UK defines the expected future as the water supply generated with the mean climate change projections coupled with the mean increase in demand (Environment Agency 2008). A Water Available for Use (WAFU), which is deployable output (DO) minus outages (time periods when the system cannot supply water), is calculated by an evaluation of how much water a system could deliver to meet a certain level of service. For example, if the level of service to be met is to require a hosepipe ban less than once every 20 years, then the conditions of an historic dry climate year or sequence of years perturbed by mean climate change coupled with a future demand regime would need to be met by a management plan that would allow for a hosepipe ban only once in 20 years. In order to accommodate uncertainty, a safety factor for headroom is added. Headroom is calculated based on the likelihood that the uncertain parameters which feed into the water resources model will appear as expected or as some other value from their probable distribution. This headroom value is added to projected demand and the management plan is revised to satisfy the balance between supply and a combination of demand plus headroom. 
The current water resources planning context provides one view of the future that summarises the relationship between WAFU, demand, and headroom based on the management option that is chosen. As an example, Fig. 1 illustrates the results of the management option for $15 \%$ Increase in Efficiency in the relationship between WAFU, demand and target headroom.

There are challenges with the EBSD approach for evaluating uncertainty in terms of analytical process and probabilistic methods. First, a level of service is decided upon often as a precursor to planning, rather than as a result of a system's ability to achieve such service based on an analysis of future conditions, and the ability to pay for the management actions required. Second, the headroom value is calculated independent of the water resources simulation. Third, the generation of a headroom value includes the assignment of probability distributions to each of the uncertain parameters and the combination of the standard deviations and means of these individual PDFs into a combined PDF for all uncertain parameters. Fourth, a Monte Carlo simulation of this combined distribution is completed, and an assumed, pre-specified percentile of this distribution is used as an overall headroom value. Finally, this obtained headroom value is then added to the demand forecast to formalise a margin of security. This final step often initiates further manual adjustments in practice. This selection routine does not account for severe uncertainty.

Severe uncertainty is a distribution of outcomes that cannot be characterized from known distribution patterns or may exhibit unpredictable behaviour in its tail ends. When dealing with severe uncertainty, such as that from climate change and variable socio-economic circumstances, it is challenging to (a) choose an accurate probability distribution for each parameter separately and especially all parameters jointly and (b) choose an appropriate percentile value from this combined distribution to represent headroom. It is also a complicated analytical sequence to quantify future conditions in a separate analytical process. The recombination of projected demand and headroom and re-evaluation of the ability of management options to achieve levels of service for both is a complex process. Management adjustments may be needed to accommodate demand plus headroom and these adjustments may change WAFU and/or demand. A change in WAFU and/or demand can influence headroom values since the calculation of headroom is intrinsically related to

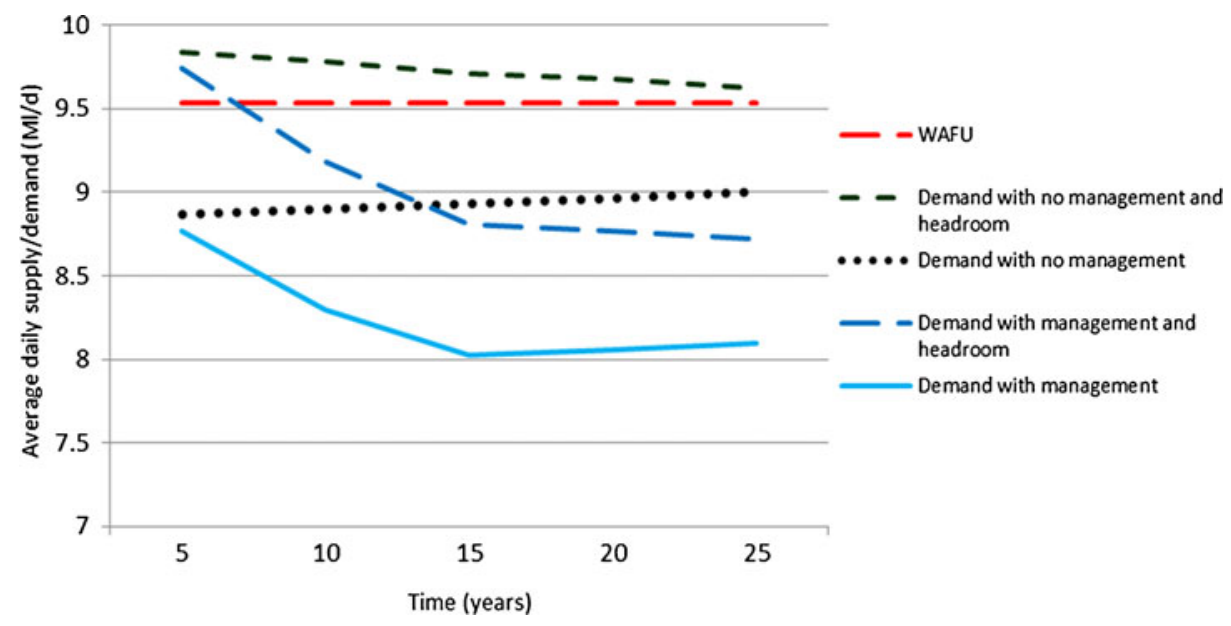

Fig. 1 Example of supply/demand balance over a 25 year planning horizon for $15 \%$ water use efficiency reductions for $75 \%$ of residential use and $100 \%$ of commercial and industrial use 
WAFU and demand. The inter-relationship of these processes can create an iterative analytical back and forth that is infeasible to bring to conclusion. In addition, the measurement values that this planning process is based on, WAFU and headroom, are not directly observable, and although they are derived from reservoir levels, some measurement of the frequency of low reservoir levels based on the range of possible supply/demand combinations would offer a less complicated assessment of a management plan's ability to handle uncertainty (cf. Hall et al. 2011).

\section{Info-Gap Based Water Resources Planning Methodology}

\subsection{Uncertainty Characterisation and Quantification}

Info-Gap decision theory provides an approach to compare the ability of different management options to satisfy system performance criteria over an unbounded range of uncertainty and has been used for decision support in many fields from engineering to conservation science (Ben-Haim 2001; Regan et al. 2005; McCarthy and Lindenmayer 2007) with one previous application related to water resources, (Hipel and Ben-Haim 1999) and one to flood risk (Hine and Hall 2010). The prospect of dealing with severe uncertainty forces preference away from what is optimum for a defined set of circumstance (to optimise) towards what is good enough over a wide range of possible circumstance (to satisfice). The simplicity of being reliant only on the central tendency of parameters to begin an assessment that addresses uncertainty is advantageous. An investigation of climate change sensitivity in terms of future temperature change (Hall et al. 2007), and an expert elicitation of the probability of tipping points occurring for different temperature rise profiles (Kriegler et al. 2009), both reveal general agreement with central tendencies but show a wide spectrum of opinions in the associated ranges.

Info-Gap decision theory offers the ability to evaluate management decisions continuously at many points in the calculation sequence as uncertain parameters increase outwards from their central tendency in an unbounded fashion. There is no requirement to take a position on how wide a range of variation should be considered. Figure 2 graphically depicts the unbounded nature of an Info-Gap assessment of a system equation with two uncertain parameters $\left(\mathrm{u}^{1}\right.$ and $\left.\mathrm{u}^{2}\right)$. The potential result of this system equation deviates from its expected result (represented by "ct") that would arise from the central tendency of both parameters, by an uncertain amount (represented by $\alpha$ ), dependent on how much each parameter deviates from its expected value. Although this figure uses a simple example with two parameters, an Info-Gap characterization of uncertainty behaves similarly with multiple parameters.

Although the uncertain space is unbounded, Info-Gap takes a targeted approach to explore this space. Other Robust Decision Making approaches (Lempert and Groves 2010; Matrosov et al. 2011) would consider multiple possible futures, but the mathematical arrangements of Info-Gap organizes the trends of all uncertain variables (no matter how many), to either increase or decrease simultaneously in two patterns: the direction of expansion into uncertainty that pushes the system in question (1) most quickly towards failure (in basic terms for water resources management, if demand increases and/or supply decreases) when considering robustness or (2) most quickly towards windfall success (in basic terms for water resources management, if demand decreases and/or supply increases) when considering opportuness. 
Fig. 2 An Info-Gap exploration of uncertainty (Hine and Hall 2010)

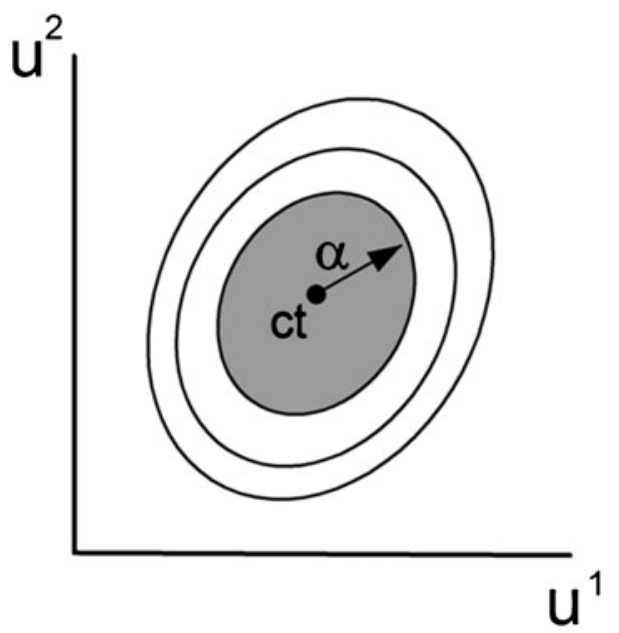

In this Info-Gap based approach, risk of water shortage is the performance criteria used in Eq. (1) to evaluate the robustness of water management options. A robust water management option has a risk of water shortage $(R)$ that is as large as possible, but still less than or equal to a critical risk value as defined by a promised level of service $\left(\mathrm{r}_{\mathrm{c}}\right)$. South West Water's promised level of service is that there will be a hosepipe ban not more often than once in 20 years. The most robust $(\widehat{\alpha})$ option $(q)$ is one that protects water supplies at the same level of risk as all the other options at the highest level of uncertainty $(\alpha)$. To quantify uncertainty and evaluate robustness, each one of the supply and demand parameters $(u)$ changes unfavourably with increasing uncertainty $(\alpha)$.

$$
\widehat{\alpha}\left(q, r_{c}\right)=\max \left\{\alpha: \max _{u \in U(\alpha, \widetilde{u})} R(q, u) \leq r_{c}\right\}
$$

The performance criteria used to evaluate opportuness is slightly different because the risk of water shortage quickly disappears as all uncertain parameters trend towards favourable conditions. Therefore, the extent of a safety margin before a risk of shortage would occur is the performance criteria used to evaluate opportuness with Eq. 2. This safety margin is defined as the volume of water between the operational management curve (which signifies the optimum reservoir volume at different times of the year), and the drought management curve (which signifies the minimum acceptable reservoir volume at different times of the year). Over the course of a year, this safety margin can be in deficit (R) by a large amount but must be less than or equal to a minimum volume of water $\left(\mathrm{r}_{\mathrm{w}}\right)$ which defines the minimum opportuness criteria. The most opportune $(\widehat{\beta})$ option $(q)$ is one that offers the same safety margin $(R)$ as other management options at the lowest level of uncertainty $(\alpha)$. To quantify uncertainty and evaluate higher levels of opportuness, each one of the supply and demand parameters $(u)$ changes favourably with increasing uncertainty $(\alpha)$.

$$
\widehat{\beta}\left(q, r_{w}\right)=\min \left\{\alpha: \max _{u \in U(\alpha, \widetilde{u})} R(q, u) \leq r_{w}\right\}
$$


Graphs of robustness and opportuness are used to compare the performance of water management options as one or more parameters trend away from their central tendency into the range of uncertainty.

Info-Gap decision theory offers a method to characterise uncertainty that works in conjunction with the simulations of a water resources model as part of an integrated dynamic analysis. There is no need to predefine levels of service and iteratively evaluate a WAFU value that satisfies these levels of service with headroom depending on the management option that is explored. Within an Info-Gap based dynamic modelling framework, the assessment of how each management option deals with uncertainty occurs through successive runs of the water resources simulation model as parameter values stray from their central tendency into greater levels of uncertainty.

The Info-Gap approach explored in this paper is similar to the Blue-Sky Stochastic Approach discussed in the Economics of Balancing Supply and Demand (NERA 2002) in that both approaches run simulations on a water resources model for a range of possible future supply and demand scenarios. The Info-Gap approach differs due to its efficient nature. It does not randomly run a plethora of possible futures, but instead evaluates all the uncertain parameters with the two trajectories that quantify robustness and opportuness. The approach introduced in this paper relies mostly on robustness curves to assess the ability of each portfolio to achieve a critical performance reward at higher levels of uncertainty as parameters trend for the worse. It also refers to opportuness curves to help qualify the relative security of a water resources system when parameters trend for the better. The knowledge of which management options fair better at higher levels of uncertainty help to inform adaptive management. Long term planning can be organised to prepare for the need to implement management options that satisfy performance needs at higher levels of uncertainty. A monitoring system can also be developed to signal when system conditions are moving towards situations that require more substantial intervention.

The major steps of the Info-Gap water resource planning methodology are:
A. Build and calibrate the simulation model of the system analysed
B. Characterise the uncertainty
C. Define the performance criteria
D. Quantify the uncertainty
E. Identify robust management strategies using MCDA

A. Build and calibrate the simulation model of the system analysed.

A time series mass balance equation, Eq. 3; storage equals the minimum of reservoir capacity or reservoir volume, plus inflow, minus the environmental flow and minus the demand.

$$
\text { storage }_{t}=\min \left\{\text { reservoir }_{\text {capacity }}, \max \left(0, \text { reservoir }_{t}+\text { inflow }_{t}-\text { envflow }_{t}-\text { demand }_{t}\right)\right\}
$$

This step is already achieved within most water resources modelling software.

B. Characterise the uncertainty.

The range of uncertainty for each parameter and the direction in terms of increase or decrease in value that pushes the system towards failure is already defined in the characterisation of headroom. The main difference in the characterisation of this uncertain space is 
that an Info-Gap approach starts at the central tendency estimate and continues to evaluate an unbounded range of values and the EBSD headroom estimation process selects one value associated with an arbitrary level of confidence from an arbitrarily assigned probability distribution. Table 1 lists all the parameters that are evaluated for uncertainty in this paper: 3 related to supply, 5 related to demand and 1 related to cost for electricity.

C. Define the system performance criteria.

The authors define a reservoir risk measure (RRM) as a comprehensive metric to quantify the risk of water shortage and compare the robustness of management options. The RRM is the product of the probability of the reservoir storage level $\left(\mathrm{S}_{\mathrm{t}}\right)$ falling below a point on a drought management curve $\left(\mathrm{D}_{\mathrm{CCt}}\right)$ and the average volume (Ml) of water deficit below this curve. This water deficit is referred to as drought deficit (DD) in this paper. A drought management curve indicates minimum acceptable reservoir volumes for different times of the year. If a reservoir volume falls below a point on this curve, then some management action may be necessary to safeguard supplies. We have created a reservoir ratio (RR) as defined in Eq. 4 to evaluate this relationship.

$$
R R=\frac{S_{t}-D c c_{t}}{D c c_{t}}
$$

If $R R>0$, the reservoir level is above the drought management curve; if $R R=0$, the reservoir level is the same as the drought management curve; if $-1<\mathrm{RR}<0$, the reservoir level is less than the drought management curve and if $R R=-1$, the reservoir is empty. The influence of uncertainty on the RR is quantified in a similar fashion as for the mass balance of the water resources simulation model explained in step D below. The RR is calculated for each stepwise exploration into the uncertain space as characterised by the Info-Gap approach. The RR value changes in response to changing reservoir storage levels.

Operational failure occurs when the reservoir is empty $(R R=-1)$ and management decisions are guided by the frequency, duration and magnitude of water shortages when $-1<\mathrm{RR}<0$ in order that $\mathrm{RR}$ never equals -1 . If the reservoir levels stay below a point on the drought management curve for a prolonged period, some form of water use restriction will be invoked. A reoccurring prolonged negative RR value would result in failure from a customer's viewpoint if it precipitated a hosepipe ban more often than the promised level of service, (i.e. once every 20 years). If the RR value remained negative for a very long period, a request for emergency water abstraction or relaxation of environmental requirements could be made in order to satisfy human needs at the detriment of resident wildlife and the local ecosystem. The DD provides more information than the RR to guide how soon a water use restriction should be put into place and how long it should last because the magnitude of the deficit is taken into account. The RRM provides a comprehensive indicator with which to compare management plans because it combines the quantification of how often a restriction may occur in the future with the magnitude of such a restriction.

The authors define a safety margin deficit (SMD) as a comprehensive metric to compare the opportuness of management options. We consider the safety margin to be the volume of water between the operational management curve, which signifies the optimum reservoir volume at different times of the year, and the drought management curve, which signifies the minimum acceptable reservoir volume at different times of the year. 


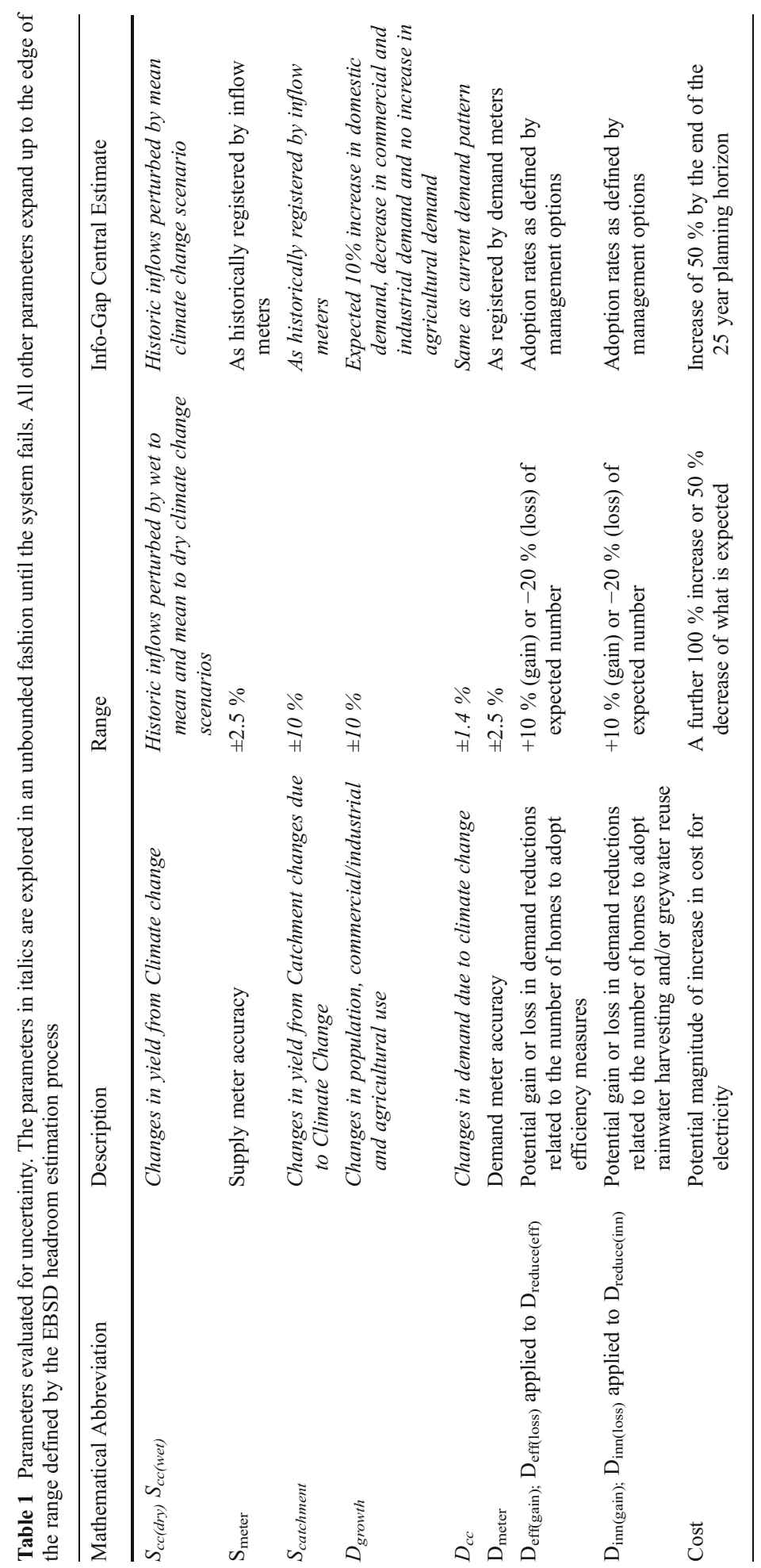


The reservoir ratio, the drought deficit and the safety margin deficit are all depicted in Fig. 3.

Other metrics are tracked as part of the MCDA analysis. Environmental impact is measured by the amount of post-reservoir stream flow. Local self-sufficiency of the system is measured by the amount of additional water requested from the regional system. Cost is measured as the sum of energy costs for the movement and treatment of water in the larger system and in the household rainwater collection and greywater reuse systems plus the costs customers must pay for the water they receive from the larger system. Carbon emissions are calculated based on the emissions related to the movement and treatment of water.

D. Quantify the uncertainty.

The water resources model simulates the mass balance of a reservoir(s) based on a sequence of historic inflow data to explore hydrologic variability over a 25 -year planning horizon. During the 25-year planning horizon domestic, agricultural and commercial/industrial demand can increase or decrease depending on circumstance. Management interventions occur at specified times over the 25-year planning horizon and adoption rates for demand side management options gradually increase over time.

To quantify uncertainty, the 25-year planning horizon is repeated multiple times; once for the baseline values of the uncertain parameters and then multiple times for further iterations to incrementally sample the range of uncertainty associated with each uncertain parameter. The exploration of uncertainty is continued beyond the expected uncertain range for the four parameters shaded blue in Table 1 or until the operational failure of an empty reservoir occurs. A summary of how each management option performs over each step into increasing uncertainty provides the data to generate the robustness and opportuness curves.

Equations 5, 6 and 7 define the evaluation of the uncertain space around supply $(S)$, demand $(D)$ and cost $(C)$. In each equation the real value for supply $(S)$, demand $(D)$ or cost (C) lies somewhere in between the nominal value minus or plus the associated incremental changes in parameter values at varying levels of uncertainty level as represented by an increasing $(\alpha)$.

$$
U s(\alpha, \widetilde{S})=\left\{\widetilde{S}-\alpha^{*}\left(\widetilde{S}_{c c(d r y)}+\widetilde{S}_{\text {meter }}+\widetilde{S}_{\text {catchment }}\right) \leq S \leq \widetilde{S}+\alpha^{*}\left(\widetilde{S}_{c c(\text { wet })}+\widetilde{S}_{\text {meter }}+\widetilde{S}_{\text {catchment }}\right)\right\}
$$

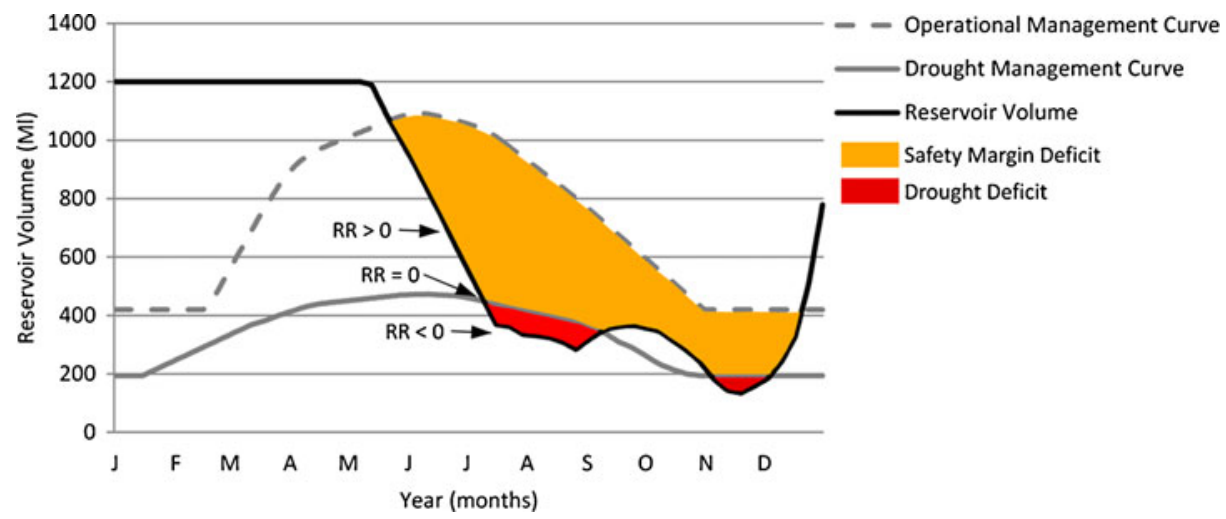

Fig. 3 Relationship of reservoir level, operational and drought management curve showing derivation of reservoir ratio $(R R)$, safety margin deficit $(S M D)$ and drought deficit $(D D)$ 


$$
\begin{aligned}
& U_{D}(\alpha, \widetilde{D})=\{\left(1+\alpha^{*} \widetilde{D}_{\text {growth }}\right) *\left(\widetilde{D}+\alpha^{*}\left(\widetilde{D}_{c c}+\widetilde{D}_{\text {meter }}\right)\right)+\underbrace{\alpha^{*} \widetilde{D}_{\text {eff(loss }} * \widetilde{D}_{\text {reduceeff) }}}_{\text {<expected_adoption_ate }}+\underbrace{\alpha^{*} \widetilde{D}_{\text {inn(loss }} * \widetilde{D}_{\text {reduce(inn) }}}_{\text {<expected_adoption_rate }} \geq D \\
& \left.\geq\left(1-\alpha^{*} \widetilde{D}_{\text {growth }}\right) *(\widetilde{D}-\alpha^{*}\left(\widetilde{D}_{c c}+\widetilde{D}_{\text {meter }}\right)-\underbrace{\alpha^{*} \widetilde{D}_{\text {eff(gain })} * \widetilde{D}_{\text {reduce(eff) }}}_{\text {>expected_adoption_rate }}-\underbrace{\alpha^{*} \widetilde{D}_{\text {inn }(\text { gain }} * \widetilde{D}_{\text {reduct(inn) }}}_{\text {>expected_adoption_ate }})\right\} \\
& U_{C}(\alpha, \widetilde{C})=\left\{\widetilde{C}-\alpha^{*}(\widetilde{C} \text { ost }) \leq C \leq \widetilde{C}+\alpha^{*}(\widetilde{C} \text { ost })\right\}
\end{aligned}
$$

Figure 4 is a plot of robustness and opportuness curves superimposed with performance results from a random combination of parameter values as defined in Eqs. 5, 6 and 7. The resulting performance criteria (minimum reservoir level), is plotted using the maximum uncertainty level of all parameters for each random combination as the y-value. The robustness curve is generated from model results when all uncertain variables trend in the direction that decreases the minimum reservoir level. The opportuness curve is generated from model results when all uncertain variables trend in the direction that increases the minimum reservoir level. This exercise confirms an appropriate formulation of the robustness and opportuness functions as all possible future results lie between the robustness and opportuness graphs.

\section{E. Identify Robust Management Strategies Using MCDA}

The most robust management plan is the one that delivers the same performance, (equal or better than the critical reward criteria), as other plans at higher levels of uncertainty. The most opportune management plan is the one that delivers the same performance, (equal or better than the minimum windfall reward criteria), as other plans at lower levels of uncertainty. Robustness curves are generated by plotting a change in RRM values, (defined in step 3 ) on the $\mathrm{x}$-axis against stepwise increases in uncertainty plotted on the $y$-axis. Opportuness curves are generated by plotting a change in SMD values on the $\mathrm{x}$-axis against stepwise increases in uncertainty plotted on the y-axis.

The decision of which water management option or combination of options is preferred, entails more than an assessment of water availability. Cost is important (cf. HM Treasury

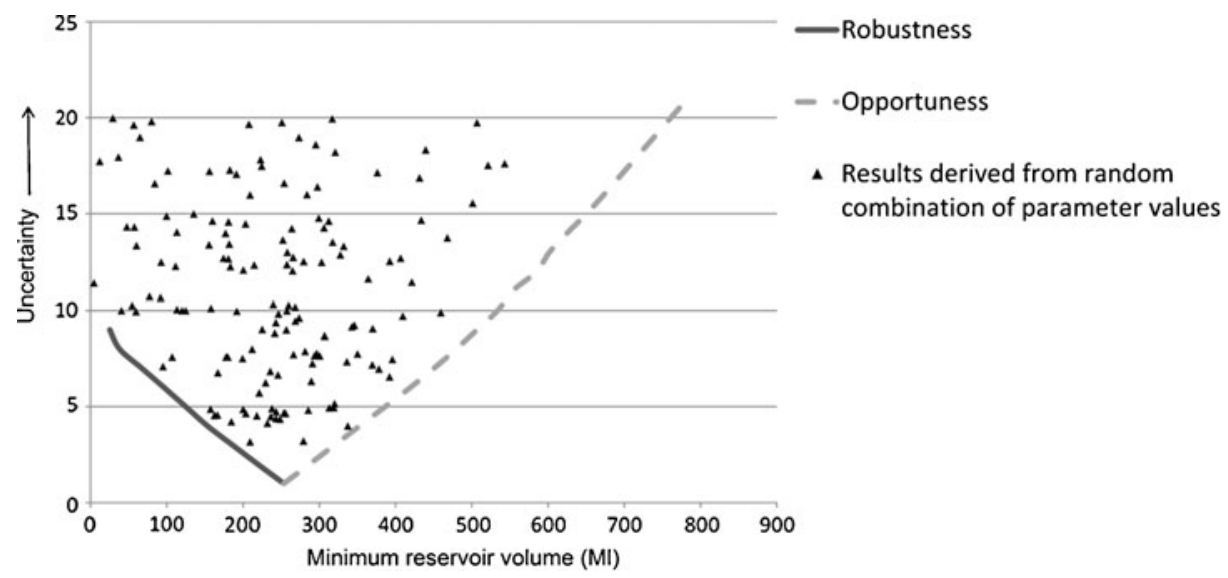

Fig. 4 Results from random parameter combinations for a management plan that promotes a $15 \%$ increase in efficiency for $50 \%$ of residences 
2011). Environmental impacts and the production of carbon emissions also need to be addressed. In this study of a local system, the draw on regional supplies is an important consideration, mainly because if weather is dry for one reservoir in a system, chances are the other reservoirs are experiencing less inflow as well and overall system resilience may depend on highly self-sufficient localised systems. Social acceptance is necessary to get a proposed management option accepted. To account for all these criteria, a variety of metrics, as listed below, are combined and evaluated with a Multi-Criteria Decision Analysis (MCDA) approach. The Info-Gap approach allows for an individual evaluation of each of the multiple criteria values.

A compromise programming MCDA method (US Army Corps 2010; Janssen 2001; Kiker et al. 2005; DCLG 2009) is used to combine the results for multiple criteria over multiple-steps of increasing uncertainty. The Info-Gap approach allows for an individual evaluation of multiple criteria. This paper aggregates multiple criteria to explore the effects of various weightings. A basic MCDA approach is used to offer maximum transparency to the weighting and resulting performance criteria (Steele et al. 2009), and because it is not designed for an optimal solution, but to offer a comparable distance to the ideal solution. A scale factor of $p=2$ is used to weight criteria proportional to their magnitude. The weighting factor, applied as in Eq. 8, is 3 for the criteria receiving the weighting factor and 1 for the remaining criteria.

$$
\text { Distance }(j)=\sum\left\{w(i)^{p} \times\left(\frac{f\left(i^{*}\right)-f(i)}{f\left(i^{*}\right)-f\left(i^{-}\right)}\right)^{p}\right\}^{1 / p}
$$

The variables used in Eq. 8 are $w(i)$ for the weight of each criteria, $f\left(i^{*}\right)$ for the optimal value, $f\left(i^{-}\right)$for the least optimal value, $f(i)$ for the criteria being evaluated and $p$ for the scaling factor, (in this case 2), (US Army Corps 2010). For the MCDA analysis in this paper, the minimum value is the optimal value and the maximum value is the least optimal value. The metric for environmental impact is inverted in order that the previously optimum maximum value for post reservoir streamflow is portrayed as an optimum minimum value in similar fashion to all the other metrics.

The six criteria evaluated using this MCDA approach are:

1. Risk of water shortage. Evaluated as a combination of robustness with the reservoir risk measure and opportuness with the safety margin deficit.

2. Environmental impact. Based on the total yearly amount of outflow from the reservoir. This study considers the environmental flow and any other outflow whether it is flow through or spillage as contributing to the total outflow from the reservoir.

3. Local self-sufficiency. Based on the additional amount of water requested from the larger regional water system

4. Cost. Based on the (1) operating costs to treat and move the water, (2) individual consumer costs for those who opted for the demand side management (DSM) actions when those management options exist and standard costs when there are no DSM management actions and (3) the total consumer cost for all residential water. An emphasis is placed on residential water use because most of the DSM options are focussed on residential use and in this case study the commercial/industrial use is a small component of total system demand. Customer costs include sewage treatment based on figures originating from South West Water 2010. The pricing is adjusted to create a tiered tariff that increases costs $10 \%$ for water use above $1301 \mathrm{pcc}$ and another $10 \%$ for use above $150 \mathrm{l}$ pcc. This tiered tariff approach is created for the sake of research and does not originate from South West Water. Costs for system operations are sourced from average 
yearly cost per unit data from SW Water. Costs for rainwater and greywater processing originate from the Urban Water Optioneering Tool (UWOT) (Makropoulous et al. 2008) model technical library and from the University of Exeter's rainwater harvesting installation at the Innovation Centre (Ward 2010). Energy and Carbon conversion factors are sourced from SW Water's Water Resource Plan (SW Water 2009), UWOT and the University of Exeter's rainwater harvesting installation.

5. Carbon footprint. Calculated from emissions in the generation of electricity related to the treatment and movement of water. The emission conversion factor is reduced over the chronological running of the model in a linear fashion to incorporate the national grid's stated climate change goals to reduce grid emissions $45 \%$ by 2020 and $80 \%$ by 2050 .

6. Social acceptability. To include social acceptability, each management option is assigned a value between 1 and 10. Reservoir expansion is considered less acceptable (assigned a value of 8), efficiency options are considered more acceptable (assigned a value of 3), innovative options such as rainwater harvesting and greywater use are considered to be in between these two (assigned a value of 5), and combination options are assigned a value of 4 .

\section{Case Study}

\subsection{Description}

This study uses a simple semi-real water resources system based on the Drift reservoir and Penzance demand node, located in southwest Cornwall, UK as shown in Fig. 5. The reservoir has a 1,200 Megalitre $(\mathrm{Ml})$ capacity which satisfies roughly $89 \%$ of the local demand. The remaining $11 \%$ is supplied from the regional Water Resource Zone which encompasses approximately the county of Cornwall. Demand is roughly $70 \%$ residential,

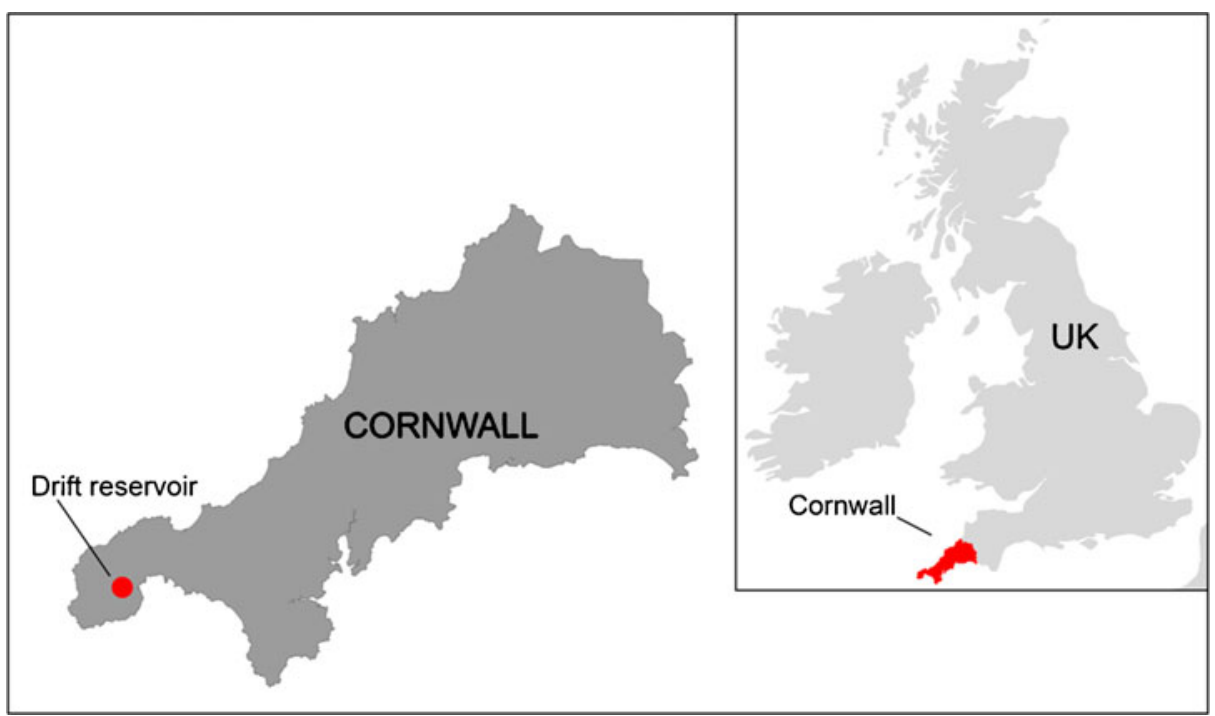

Fig. 5 Study area location 
$20 \%$ commercial/industrial and $10 \%$ agricultural. If the required demand is greater than the local abstraction limits of 10.91 Megaliters per day (M1/d), the remaining demand is sourced from regional supply. There is an additional $0.5 \mathrm{Ml} / \mathrm{d}$ supplied by the regional system if the Drift reservoir falls below its operational curve and an additional $2.0 \mathrm{Ml} / \mathrm{d}$ supplied by the regional system if the Drift reservoir falls below a point on a point on its drought management curve. This curve defines the optimal reservoir volume for the time of year based on historic weather patterns. Due to gardening needs and an influx of tourists, summer demands can be as much as $35 \%$ higher than winter demands, all at a time when summer flows are low. Although, it may be more common for environmental requirements to vary between summer and winter, in the Drift catchment there is a required base environmental flow of $1.36 \mathrm{Ml} / \mathrm{d}$ at all times throughout the year.

The daily time step water resources model used in this research is constructed in MATLAB. Look-up tables hold time series values to serve the parameter needs of the water reservoir mass balance Eq. 1. These parameters include: daily inflow and rainfall values over a 25 year period from 1962 to 1986 inclusive, average weekly demand factors that show an increase in use during the summer months and a slight reduction in the winter, and UKWIR climate change flow factors to quantify the effects of climate change on future river flows. These flow factor values are sourced from SW Water and guided by the final UKWIR CL04 Method 1methodology of December 2008 (UKWIR 2009). In the MATLAB code are baseline values for per capita demand, population in terms of the number of houses, commercial and industrial combined demand, and agricultural demand. Growth factors for each of these three demand components project an expected increase of $10 \%$ in population, a drop of $10 \%$ in commercial and industrial demand and an increase of $5 \%$ in agricultural demand.

\subsection{Uncertainty Sources}

As mentioned in section 3 of the Info-Gap based water resources planning methodology sequence, uncertainty is explored for three supply-side parameters, five demandside parameters and cost (see Table 1). With the EBSD headroom estimation approach most of these parameters are assigned a probability distribution based on a percent variation from the expected value. With normal distributions the range of variation is centred on zero and the percent deviation equates roughly to two standard deviations. With triangular distributions the mean value is the expected forecast and the best and worst cases are either percent deviations or defined values as is the case with the uncertainty of climate change impact on source yield. The climate change impact parameter is considered a triangular distribution guided by values predicted for the wet, mid and dry scenario inflows. Other parameters include: accuracy of supply-side meters (normal distribution with $5 \%$ variation), climate change impact on catchment process (normal distribution with $10 \%$ variation), accuracy of demand-side meters (normal distribution with $2.5 \%$ variation), demand forecast variation (triangular distribution with $10 \%$ variation), impact of climate change on demand (triangular distribution centred on a $1.4 \%$ increase with a range of $20 \%$ variation either side of this increase), and adoption of efficiency measure (triangular distribution with a potential increase in adoption rate of $10 \%$ and drop in adoption rate of $20 \%$ ).

This Info-Gap approach uses the same central tendency values as the headroom approach, (for example, inflow values associated the climate change mid scenario or the expected population growth), but instead of selecting a percentile value from each parameter's assumed distribution as with the headroom approach, the Info-Gap calculation sequence 
samples the full range of this uncertainty and beyond for the four parameters shaded in blue in Table 1 or until the system fails.

\subsection{Water Resource management options}

This study explores the relative performance of 81 different management options: 8 different supply side options, 9 different efficiency related options, 60 different domestic rainwater and greywater options and 4 different combination strategies. Such a large number of options are explored to assess the extent of intervention needed to achieve significant management results. For instance, is an increase in reservoir volumes from 1,200 Ml to $1,400 \mathrm{Ml}$ enough or is $1,600 \mathrm{Ml}$ or $1,800 \mathrm{Ml}$ needed? Would efficiency reductions of $10 \%$ in $50 \%$ of households suffice or would the reductions need to be $15 \%$ in $75 \%$ of households to make an impact, and how many homes would need to incorporate greywater and/or rainwater use to help the overall system achieve a positive supply/demand balance?

The range of 81 options explored includes:

1. Increase reservoir volume from $1,200 \mathrm{Ml}$ to $1,400 \mathrm{Ml}, 1,600 \mathrm{Ml}$ or 1,800 $\mathrm{Ml}$ at the end of the third periodic review of the planning horizon, on the 15 th year (4 options).

2. Immediate increase of transfers from regional system when reservoir falls below operating curve from $1 \mathrm{Ml} / \mathrm{d}$ to $1.5,2$ and $2.5 \mathrm{Ml} / \mathrm{d}$ (3 options).

3. Immediate increase of water treatment capabilities from $11 \mathrm{Ml} / \mathrm{d}$ to $13 \mathrm{Ml} / \mathrm{d}$ and increase yearly abstraction limit to allow for an increase in abstraction of $1.364 \mathrm{Ml} / \mathrm{d}$ (1 option).

4. An increase in efficiency of $5 \%, 7.5 \%, 10 \%, 12.5 \%$ and $15 \%$ for a third of residential homes. Efficiency reductions of $15 \%$ were also modelled for $50 \%, 66 \%, 75 \%$ and $90 \%$ of residential homes. Efficiency reductions start gradually and make their maximum impact by the midpoint of the planning horizon, before the 15 th year. Efficiency reductions include commercial and industrial use with the assumption that reductions would be achieved with all commercial and industrial operations ( 9 options).

5. Domestic rainwater collection for (R1) toilets only, (R2) toilets and outside use, (R3) with the addition of clothes washers and (R4) with the addition of bathing water for $33 \%, 50 \%, 66 \%, 75 \%$ and $90 \%$ of residential homes. The adoption of rainwater collection practices increases incrementally with a third of all adoptees starting the practice in the first 5 years, followed by two-thirds in the next 5 years and the final third before the 15 th year. The assumed cistern size ranged initially from 500 to 7,500 1. Final simulations concentrated on cistern sizes of 2,400 1 as this size showed significant gains for each rainwater use scenario. The assumed roof size is $50 \mathrm{~m}^{2}$. It is important to have a rainwater cistern at least as large as 2,400 1 to show significant reductions in water demand from the mains (25 options).

6. Domestic greywater use for (G1) toilets only, (G2) toilets and outside use for $33 \%$, $50 \%, 66 \%, 75 \%$ and $90 \%$ of residential homes. The adoption of domestic greywater practices increases incrementally with a third of all adoptees starting the practice in the first 5 years, followed by two-thirds in the next 5 years and the final third before the 15 th year. For higher adoption rates of 50-90\%, the increases during each 5 year period are proportionately higher (10 options).

7. Rainwater collection for bathing and clothes washing and greywater for toilets and outside use $(\mathrm{R} / \mathrm{G})$ for $33 \%, 50 \%, 66 \%, 75 \%$ and $90 \%$ of residential homes. The adoption of combined greywater use and rainwater collection increases incrementally with a third of all adoptees starting the practice in the first 5 years, followed by twothirds in the next 5 years and the final third before the 15th year (25 options). 
8. Other management option combinations include: greywater use for toilets with a $50 \%$ adoption rate and an additional $1 \mathrm{Ml}$ regional transfer; increased efficiency with a $50 \%$ adoption rate and an additional $1 \mathrm{Ml}$ regional transfer; greywater for toilets and increased efficiency each with a $50 \%$ adoption rate; and rainwater for bathing and clothes washing, greywater for toilets and outside use and increased efficiency - each with an adoption rate of $1 / 3$ of all homes. These combination strategies follow a similar pattern to the individual interventions of slowly ramping up adoption rates over a 15 year period (four options).

\subsection{Results and Discussion}

As mentioned in the methodology section, the Info-Gap approach characterises the uncertainty of parameters that are input into a water resources model. The quantification of uncertainty requires repeated simulations of the model as uncertain parameters stray from their central tendency through the uncertainty range of each uncertain parameter $10 \%$ of this range at a time, and beyond for four parameters; climate change effect on (1) source yield, (2) catchment change and (3) domestic demand and (4) growth in terms of population, commercial/industrial and agricultural activity. A summary of how each metric performs during each of these simulation steps into increasing uncertainty provides the base data to generate the robustness and opportuness curves.

Figure 6 shows the robustness curves for a selection of the management options explored in terms of their performance relative to the reservoir risk measurement (RRM). This figure shows that valuable information can be gathered from the performance of management options beyond the range of uncertainty explored with the EBSD headroom estimation process (depicted by the dark blue dashed box). This dark blue dashed box shows the range of performance values that result from an interplay of the parameter values found in the probabilistic range between confidence levels $75 \%$ and $85 \%$. At the edge of this confidence level range, three strategies fail; two options with rainwater collection only and the efficiency only option. Many other strategies fail before level 10 of increasing uncertainty on the y-axis, which marks the edge of the uncertainty range as defined in the EBSD approach; reservoir expansion of 200Ml, an increase

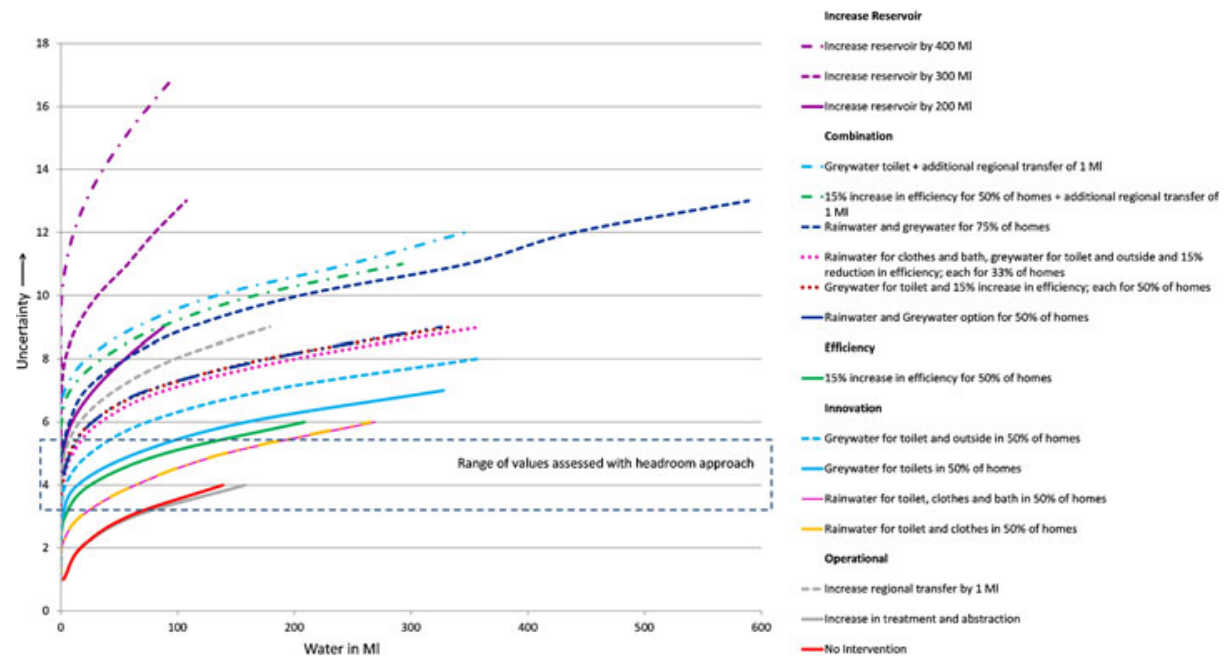

Fig. 6 Robustness of different management strategies as assessed by a reservoir risk measure (RRM); the product of the probability of the reservoir falling below the drought management curve and the average volume (Ml) of water deficit below this curve 
in regional transfer of $1 \mathrm{Ml}$, greywater only adopted by $50 \%$ of homes, rainwater and greywater reuse adopted by $50 \%$ of homes and the combined demand side management option of rainwater, grey water and efficiency at an adoption rate of $33 \%$ of homes each. Only the combinations of increased efficiency or greywater reuse in $50 \%$ of homes plus additional regional transfer, rainwater and greywater reuse adopted by $75 \%$ of homes and the reservoir expansion of $300 \mathrm{Ml}$ or $400 \mathrm{Ml}$ are robust enough to make it past level 10 of increasing uncertainty.

Just before level 10, there is preference reversal between the reservoir expansion of $200 \mathrm{Ml}$ and rainwater and greywater combined option with $75 \%$ adoption rate. This preference reversal is manifested as a crossing of the corresponding robustness curves: solid purple for reservoir expansion and dash - blue for rainwater/gerywater. At lower values of the RRM (below approx. $60 \mathrm{Ml}$ ), the rainwater and greywater combined option is more robust, but beyond this RRM value, the reservoir expansion of $200 \mathrm{Ml}$ is more robust (for a short period), meaning it can provide the same level of performance at higher levels of uncertainty. The reservoir expansion of $200 \mathrm{Ml}$ option trends in a direction to be more robust than the efficiency and greywater options with additional regional transfer, but fails before it can. In the long term, preference returns for the rainwater and greywater combined option with $75 \%$ adoption rate as it proves more robust than the reservoir expansion of $200 \mathrm{Ml}$ option. The robustness curves show that a substantial increase in reservoir volume is needed for a significantly robust option. It is interesting to note that the efficiency and greywater options with additional regional transfer are the most robust demand side management (DSM) option while they last, but at approximately level 12 and 14 respectively both these options fail. Although the rainwater and greywater combined option with $75 \%$ adoption rate is less robust than these two DSM options at lower levels of uncertainty, it is more robust in the long term because it eludes failure until uncertainty level 14. Evaluating the robustness of management options past the range assessed with the EBSD headroom approach provides more information to differentiate the value of different options. Within the dashed blue line box, most options perform reasonably well. Which options fail first is only revealed outside of this box at higher uncertainties

Figure 7 shows the opportuness curves for a selection of the management options explored in terms of their relative success based on the safety margin deficit (SMD). The management options that are successful enough to survive failure beyond level 6 of increasing uncertainty (the extent of the range of uncertainty evaluated as part of the
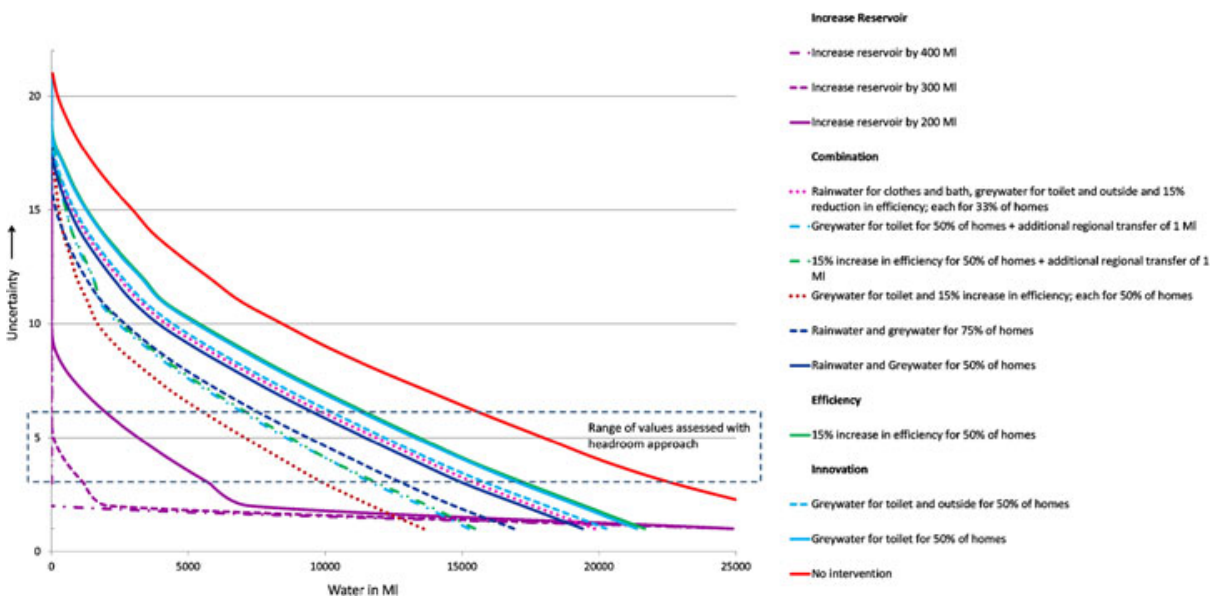

Fig. 7 Opportuness of different management strategies as assessed by safety margin deficit (SMD) 
EBSD headroom estimation), are included in these opportuness curves to see if their performance under auspicious conditions provides further insight into their merit. This graph shows that the reservoir expansion options are the quickest to lessen the SMD, followed by the combined demand side management option of greywater use for toilets and increased efficiency each in $50 \%$ of homes. At lower efficiencies, a close third and fourth to lessen the SMD are the demand side management options of greywater for toilets and increased efficiency both with additional regional water transfer. At higher efficiencies however, these two options are outperformed by the rainwater and greywater combinations at $75 \%$ and $50 \%$ adoption rates, respectively. These preference reversals highlight the fact that rainwater harvesting lessens the demand for water from reservoirs, and contributes to a quicker return to a positive water balance with a greater safety margin.

Figure 8 shows the probability that the reservoir level will fall below the drought control curve for 13 of the best performing management options and the no intervention option for comparison. The probability curves show erratic behaviour with the probability increasing and decreasing with increasing uncertainty due to the fact that reservoir levels can move up and down in relation to points on the drought management curve more than once each year. This behaviour creates a mess of crossing lines. The use of the RRM in Fig. 6 creates cleaner plots and shows a consistent trend for the security of a reservoir because it takes into account the combination of frequency and magnitude in an overall measure. The RRM as a performance indicator offers a much clearer view of the relative merit of management options.

The only options that ensure a reservoir volume will not drop below a point on a drought management curve more than once in 20 years (termed below as the 'once in 20 years test')are the reservoir expansion options,. A willingness to endure the reservoir volume dropping below a point on the drought management curve more often, up to once in 10 years (termed below the 'once in 10 years test'), allows for the consideration of a variety of other management options. Taking into account the fact that the probability of an occurrence is not as important as its magnitude, the robustness curves based on the RRM show that many DSM options that pass the 'once in 10 years test' but not the 'once in 20 years test' perform relatively well. In fact, three of these DSM options avoid operational failure at much higher levels of uncertainty than the reservoir expansion option of $200 \mathrm{Ml}$, which passes the 'once in 20 years test'.

Table 2 lists the ranking of management options as a result of an MCDA performance evaluation based on different weightings for each of the six criteria listed in section 3.2. For

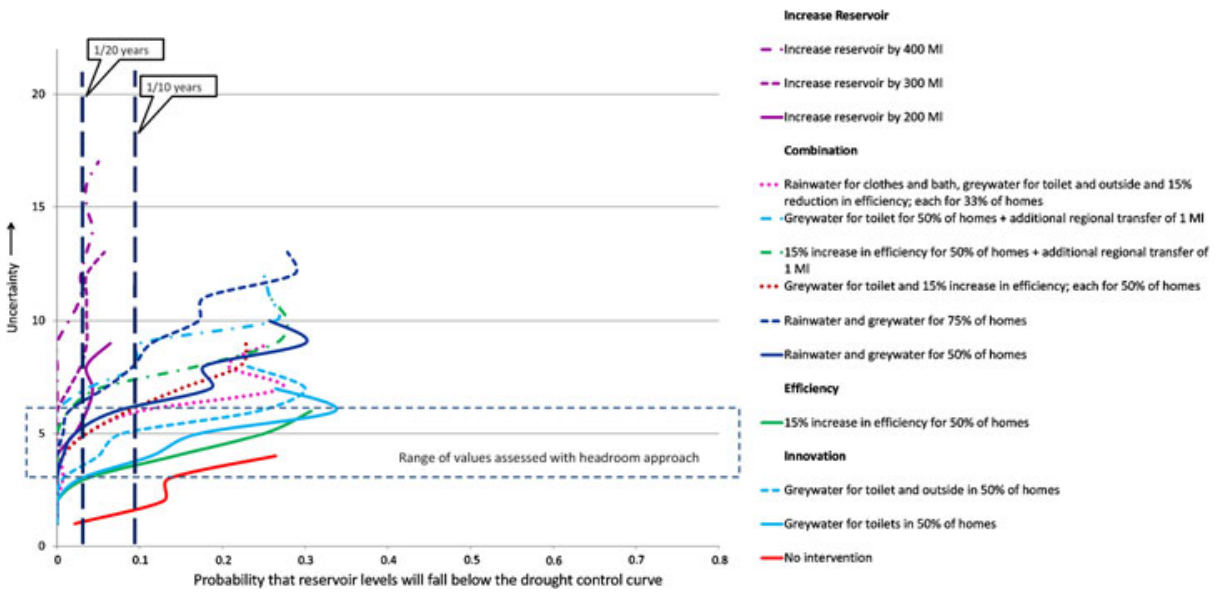

Fig. 8 Probability that reservoir levels will fall below the drought control curve 
Table 2 Multi-Criteria Decision Analysis performance evaluation with different weightings. The far right column of the table provides a key to the colour coding that is designed to help easy identification of which type of management intervention performed well over the most criteria and also where preference reversal occurred at higher uncertainties that might not have been noticed within the range assessed with the current headroom calculation

\begin{tabular}{|c|c|c|c|c|c|c|c|}
\hline \multirow{2}{*}{ Rank } & \multicolumn{2}{|l|}{ Equal Weighting } & \multicolumn{2}{|c|}{ Emphasis on Water Availability } & \multicolumn{2}{|c|}{ Emphasis on Environment } & \multirow{2}{*}{$\begin{array}{l}\text { Table Legend } \\
\text { *Refer to } 4.2 \text { for more details }\end{array}$} \\
\hline & Low Uncertainty & High Uncertainty & Low Uncertainty & High Uncertainty & Low Uncertainty & High Uncertainty & \\
\hline 1 & $\mathrm{G}(\mathrm{t}) / \mathrm{E}$ at $50 \%$ & $\mathrm{R} / \mathrm{G}$ at $75 \%$ & $\mathrm{G}(\mathrm{t}) / \mathrm{E}$ at $50 \%$ & $\mathrm{R} / \mathrm{G}$ at $75 \%$ & $\begin{array}{l}\mathrm{R} / \mathrm{G} / \mathrm{E} \text { at } 33 \% \\
\text { each }\end{array}$ & $\mathrm{R} / \mathrm{G}$ at $75 \%$ & Res $+X X X M \mid=$ Reservoir increase \\
\hline 2 & $R / G / E$ at $33 \%$ each & $\begin{array}{l}\text { E at } 50 \% \& \mathrm{~T}+ \\
1 \mathrm{Ml}\end{array}$ & Res $+400 \mathrm{Ml}$ & $\begin{array}{l}\text { E at } 50 \% \& \mathrm{~T}+ \\
1 \mathrm{Ml}\end{array}$ & $\mathrm{R} / \mathrm{G}$ at $75 \%$ & $\begin{array}{l}\text { E at } 50 \% \& T^{+} \\
1 \mathrm{Ml}\end{array}$ & $\begin{array}{l}\mathrm{G}=\text { greywater, }(\mathrm{t})=\text { toilet, }(\mathrm{o})= \\
\text { outside }\end{array}$ \\
\hline 3 & $\mathrm{R} / \mathrm{G}$ at $75 \%$ & $\begin{array}{l}\mathrm{G}(\mathrm{t}) \text { at } 50 \% \& \mathrm{~T}+ \\
1 \mathrm{Ml}\end{array}$ & Res $+300 \mathrm{Ml}$ & $\begin{array}{l}\mathrm{G}(\mathrm{t}) \text { at } 50 \% \& \mathrm{~T}+ \\
1 \mathrm{Ml}\end{array}$ & $\mathrm{G}(\mathrm{t}) / \mathrm{E}$ at $50 \%$ & $\begin{array}{l}\mathrm{G}(\mathrm{t}) \text { at } 50 \% \& \mathrm{~T}+ \\
1 \mathrm{Ml}\end{array}$ & $\mathrm{R} / \mathrm{G}=$ Rainwater and greywater \\
\hline 4 & $\mathrm{R} / \mathrm{G}$ at $50 \%$ & Res + 400Ml & Res + 200Ml & Res + 400Ml & $\mathrm{R} / \mathrm{G}$ at $50 \%$ & Res + 400Ml & $\mathrm{E}=$ Efficiency \\
\hline 5 & $\mathrm{G}(\mathrm{t}+\mathrm{o})$ at $50 \%$ & Res $+300 \mathrm{Ml}$ & $\mathrm{R} / \mathrm{G}$ at $75 \%$ & Res $+300 \mathrm{Ml}$ & $\mathrm{G}(\mathrm{t}+\mathrm{o})$ at $50 \%$ & Res $+300 \mathrm{Ml}$ & $\begin{array}{l}\text { R/G/E = Rainwater, Greywater, } \\
\text { Efficiency }\end{array}$ \\
\hline & E at $50 \% \& \mathrm{~T}+1 \mathrm{Ml}$ & & $\begin{array}{l}\mathrm{G}(\mathrm{t}) \text { at } 50 \% \& \mathrm{~T}+ \\
1 \mathrm{MI}\end{array}$ & & $\begin{array}{l}\text { E at } 50 \% \& T_{+} \\
1 \mathrm{Ml}\end{array}$ & & $\begin{array}{l}\mathrm{G}(\mathrm{t}) / \mathrm{E}=\mathrm{Greywater} \text { for toilet, } \\
\text { Efficiency }\end{array}$ \\
\hline 7 & $\begin{array}{l}\mathrm{G}(\mathrm{t}) \text { at } 50 \% \& \mathrm{~T}+ \\
1 \mathrm{MI}\end{array}$ & & $\begin{array}{l}\text { E at } 50 \% \& \mathrm{~T}+ \\
1 \mathrm{Ml}\end{array}$ & & $\begin{array}{l}\mathrm{G}(\mathrm{t}) \text { at } 50 \% \& \mathrm{~T}+ \\
1 \mathrm{Ml}\end{array}$ & & $\& \mathrm{~T}-1 \mathrm{Ml}=$ extra regional transfer \\
\hline 8 & $\mathrm{G}(\mathrm{t})$ at $50 \%$ & & $\begin{array}{l}\mathrm{R} / \mathrm{G} / \mathrm{E} \text { at } 33 \% \\
\text { each }\end{array}$ & & E at $50 \%$ & & operating curve \\
\hline 9 & E at $50 \%$ & & $\mathrm{R} / \mathrm{G}$ at $50 \%$ & & $\mathrm{G}(\mathrm{t})$ at $50 \%$ & & "at $\times \%$ " denotes the adoption \\
\hline 10 & Res $+400 \mathrm{Ml}$ & & $\mathrm{G}(\mathrm{t}+\mathrm{o})$ at $50 \%$ & & Res + 400Ml & & \\
\hline
\end{tabular}

\begin{tabular}{|c|c|c|c|c|c|c|c|c|}
\hline \multirow{2}{*}{ Rank } & \multicolumn{2}{|c|}{ Emphasis on Local self-sufficiency } & \multicolumn{2}{|l|}{ Emphasis on Cost } & \multicolumn{2}{|c|}{ Emphasis on Carbon } & \multicolumn{2}{|c|}{ Emphasis on Social Acceptability } \\
\hline & Low Uncertainty & High Uncertainty & Low Uncertainty & High Uncertainty & Low Uncertainty & High Uncertainty & $\begin{array}{l}\text { Low } \\
\text { Uncertainty }\end{array}$ & $\begin{array}{l}\text { High } \\
\text { Uncertainty }\end{array}$ \\
\hline 1 & $R / G / E$ at $33 \%$ each & $\mathrm{R} / \mathrm{G}$ at $75 \%$ & $\mathrm{R} / \mathrm{G}$ at $75 \%$ & $\mathrm{R} / \mathrm{G}$ at $75 \%$ & $\begin{array}{l}R / G / E \text { at } 33 \% \\
\text { each }\end{array}$ & $\begin{array}{l}\mathrm{G}(\mathrm{t}) \text { at } 50 \% \& \mathrm{~T}+ \\
1 \mathrm{MI}\end{array}$ & $\begin{array}{l}\mathrm{R} / \mathrm{G} / \mathrm{E} \text { at } 33 \% \\
\text { each }\end{array}$ & $\begin{array}{l}G(t) \text { at } 50 \% \text { \& } \\
T+1 M l\end{array}$ \\
\hline 2 & $\mathrm{R} / \mathrm{G}$ at $75 \%$ & $\begin{array}{l}\text { E at } 50 \% \& T^{+} \\
1 \mathrm{Ml}\end{array}$ & $\begin{array}{l}R / G / E \text { at } 33 \% \\
\text { each }\end{array}$ & $\begin{array}{l}E \text { at } 50 \% \& T^{+} \\
1 \mathrm{Ml}\end{array}$ & $\mathrm{G}(\mathrm{t}) / \mathrm{E}$ at $50 \%$ & Res $+400 \mathrm{Ml}$ & $\mathrm{G}(\mathrm{t}) / \mathrm{E}$ at $50 \%$ & $\mathrm{R} / \mathrm{G}$ at $75 \%$ \\
\hline 3 & $\mathrm{G}(\mathrm{t}) / \mathrm{E}$ at $50 \%$ & $\begin{array}{l}\mathrm{G}(\mathrm{t}) \text { at } 50 \% \& \mathrm{~T}+ \\
1 \mathrm{Ml}\end{array}$ & $\mathrm{G}(\mathrm{t}) / \mathrm{E}$ at $50 \%$ & $\begin{array}{l}\mathrm{G}(\mathrm{t}) \text { at } 50 \% \& \mathrm{~T}+ \\
1 \mathrm{MI}\end{array}$ & $\begin{array}{l}\mathrm{E} \text { at } 50 \% \& \mathrm{~T}+ \\
1 \mathrm{MI}\end{array}$ & $\mathrm{R} / \mathrm{G}$ at $75 \%$ & $\mathrm{R} / \mathrm{G}$ at $50 \%$ & Res + 400Ml \\
\hline 4 & $\mathrm{R} / \mathrm{G}$ at $50 \%$ & Res $+400 \mathrm{Ml}$ & $\mathrm{R} / \mathrm{G}$ at $50 \%$ & Res $+400 \mathrm{Ml}$ & E at $50 \%$ & $\begin{array}{l}E \text { at } 50 \% \& T+ \\
1 \mathrm{MI}\end{array}$ & $\begin{array}{l}\mathrm{E} \text { at } 50 \% \& \mathrm{~T}+ \\
1 \mathrm{Ml}\end{array}$ & $\begin{array}{l}E \text { at } 50 \% \& T \\
+1 \mathrm{Ml}\end{array}$ \\
\hline 5 & $G(t+0)$ at $50 \%$ & Res + 300Ml & $G(t+0)$ at $50 \%$ & Res + 300Ml & Res + 400Ml & Res $+300 \mathrm{Ml}$ & E at $50 \%$ & Res + 300Ml \\
\hline 6 & $\mathrm{G}(\mathrm{t})$ at $50 \%$ & & $\mathrm{G}(\mathrm{t})$ at $50 \%$ & & Res + 300MI & & $\mathrm{R} / \mathrm{G}$ at $75 \%$ & \\
\hline 7 & Res + 400Ml & & E at $50 \%$ & & Res + 200Ml & & $G(t+0)$ at $50 \%$ & \\
\hline 8 & E at $50 \%$ & & $\begin{array}{l}\mathrm{G}(\mathrm{t}) \text { at } 50 \% \& \mathrm{~T}+ \\
1 \mathrm{Ml}\end{array}$ & & $\mathrm{R} / \mathrm{G}$ at $50 \%$ & & $\begin{array}{l}\mathrm{G}(\mathrm{t}) \text { at } 50 \% \& \mathrm{~T} \\
+1 \mathrm{Ml}\end{array}$ & \\
\hline 9 & Res + 300Ml & & $\begin{array}{l}\text { E at } 50 \% \& \mathrm{~T}+ \\
1 \mathrm{Ml}\end{array}$ & & $\begin{array}{l}\mathrm{G}(\mathrm{t}) \text { at } 50 \% \& \mathrm{~T}+ \\
1 \mathrm{Ml}\end{array}$ & & $\mathrm{G}(\mathrm{t})$ at $50 \%$ & \\
\hline 10 & Res + 200Ml & & Res + 400Ml & & $\mathrm{G}(\mathrm{t})$ at $50 \%$ & & Res + 400Ml & \\
\hline
\end{tabular}

simplicity's sake, the rankings for each criteria grouping are presented for only two levels of uncertainty that represent low and high uncertainty instead of a ranking for each of the 20 steps of increasing robustness. Low uncertainty refers to level 5 of increasing uncertainty in 
Figs. 4, 6, 7 and 8. Level 5 is range of uncertainty used to generate the headroom value in the EBSD headroom estimation approach. High uncertainty refers to level 10 of increasing uncertainty in the same figures. Level 10 is the range of uncertainty associated with the outer boundary of the uncertainty range as defined in the EBSD headroom estimation approach. A rank of 1 indicates a management option that performs the best over multiple criteria.

At lower uncertainties the highest ranked four options are the same with some change in order for all weightings except emphasis on water availability, carbon and social acceptability. These top four DSM options; Rainwater/Greywater/Efficiency (R/G/E in light pink coloured cells), Greywater/Efficiency (G(t)/E in brick red coloured cells) and Rainwater/Greywater adoption rates of $75 \%$ and $50 \%$ (R/G in darker blue coloured cells) perform well because they offer a balance of benefits that satisfy a wide range of criteria and the DSM measures have high adoption rates. Most of these DSM options are outperformed in the water availability weighting at lower uncertainties because the reservoir expansion options perform so well in terms of robustness and opportuness for water availability. Management options that include efficiency rise in the rankings to the top four with the carbon and social acceptability weightings because efficiency saves on carbon created during the treatment and distribution of water and because efficiency is classified as one of the most socially acceptable options. The reservoir expansion options rank low in all cases except for low and high uncertainty for water availability because the ability of these options to alleviate a risk of water shortage is not significant enough to counteract lower performance in other criteria.

Only five management options succeed at higher uncertainties. The preference for including efficiency measures at lower uncertainties with the Rainwater/Greywater/Efficiency (R/G/E in light pink coloured cells) and Greywater/Efficiency $(\mathrm{G}(\mathrm{t}) / \mathrm{E}$ in brick red coloured cells) options is replaced by a preference for increased supply with additional regional transfers and significantly high adoption rates with the rainwater and greywater use occurring each in $75 \%$ of homes. At higher uncertainties the need for more water exerts such a significant influence to overbalance the carbon and socially acceptable weightings. For these weightings, one would expect the Efficiency plus additional regional transfer option to rate high because increased efficiency means decreased carbon use and efficiency is also more socially acceptable. However, the top three ranked options at higher uncertainties for the carbon and socially acceptable weightings outperform the efficiency option with regional transfer because, on balance, they either supply more water or reduce water use more effectively at higher uncertainties.

It is interesting to note that the combined volume of all the cisterns in any management option that includes rainwater collection ranges from $14 \mathrm{Ml}$ to $18 \mathrm{Ml}$ at the beginning and end of the planning horizon for adoption rates in $50 \%$ of homes; and $31 \mathrm{Ml}$ to $40 \mathrm{Ml}$ for adoption rates in $75 \%$ of homes. This volume is significantly smaller than the volumes that are added to the reservoir in the reservoir expansion options. The reason such a small volume can have such a large impact is because use over the year lessens the requirement for more water from the reservoir, thus making it easier to keep reservoir levels higher. Also, the frequent use of a small-scale system means there is little chance of spill over and wasted water. Whereas with a reservoir, there is lots of water that spills over without ever contributing to the system's needs, unless of course there is a large enough reservoir, like the one expanded by $400 \mathrm{Ml}$, with enough space to keep more of this water for the summer season.

\section{Conclusion}

The results of this study show that an Info-Gap based water resources planning methodology offers a broader understanding of how different management options perform over a wider 
range of plausible futures than is explored with traditional water resource planning methods such as the EBSD headroom estimation process used in England and Wales. The discussion in section 4.4 highlights the fact that many management options that perform well within the EBSD 'headroom range of uncertainty' fail just beyond this range, while others continue to perform at much higher levels of uncertainty. This study also shows that preference reversals can occur at higher uncertainties. This is important because an approach focused on robust decision-making is less likely to be constrained by epistemological limits and therefore more likely to succeed than an approach focused on optimal decision-making predicated on the predictive accuracy of climate models (Dessai et al. 2009).

The inclusion of MCDA facilitates the assessment of each management option over multiple metrics in order to highlight differently weighted performance results that might influence adaptive management choices. A balanced assessment of the performance of management options over a range of criteria shifts the focus away from reservoir expansion options that perform best in regards to water availability at lower uncertainties. This is also important because when responding to climate change, there is a danger of maladaptation if not all metrics or water resource issues are taken into account. (Barnett and O'Neill 2009)

This Info-Gap based approach offers the technical platform to address some of the needed improvements to the current water resources planning process as noted by Hall et al. (2011). These Info-Gap based improvements include: the ability to directly evaluate levels of service in terms of more observable outcomes than deployable output (DO) as exemplified by the reservoir ratio (RR), the reservoir risk measure (RRM) and the safety margin deficit (SMD); the integration of uncertainty analysis within the water resource system simulation process; and the ability to evaluate and compare management options over a wide range of plausible futures.

The Info-Gap tact to combine all the trends of uncertain parameters into a worst case future trajectory is appealing in terms of its efficiency. However, it is not certain that management options that are preferred when all parameters push system towards failure will also be preferred when the uncertainty related to supply and demand increases or decreases in different patterns.

Future research is currently underway to use an Info-Gap based water resources management approach to evaluate a more complex regional water supply system, to use UKCP09 probabilistic climate change projections to drive future changes in water resources availability and to test if variable trends of uncertainty related to supply and demand reveal a preference in management options different than that chosen with the robustness curves.

Acknowledgements The authors are grateful to three anonymous referees for their detailed comments. Any errors remain our own. Brett Korteling is supported by the University of Exeter's Climate Change and Sustainable Futures theme. South West Water are thanked for their generosity in terms of their time and data. Suraje Dessai was supported by the ARCC-Water project funded by EPSRC (EP/G061181/1) and the EQUIP project funded by NERC (NE/H003509/1).

\section{References}

Arnell NW (1998) Climate change and water resources in Britain. Clim Chang 39(1):83-110

Arnell NW (2011) Incorporating climate change into water resources planning in England and Wales. J Am Water Works Assoc 47(3):541-549

Arnell NW, Delaney EK (2006) Adapting to climate change: public water supply in England and Wales. Clim Chang 78(2):227-255. doi:10.1007/s10584-006-9067-9

Barnett J, O’Neill S (2009) Maladaption. Global Env Chang 20:211-213 
Bates BC, Kundzewicz ZW, Wu S, Palutikof JP (eds) (2008) Clim Chang Water. Technical Paper of the Intergovernmental Panel on Climate Change, IPCC Secretariat. Geneva, pp 210

Ben-Haim Y (2001) Information-Gap decision theory: decisions under severe uncertainty, 2nd edn. Wiley, New York

Collins KB, Ray LI (2009) Trusting emergence: some experiences of learning about integrated catchment science with the environment agency of England and Wales. Water Resour Manag 24(4):669-688

Darch G, Arkell B, Tradewell J (2011) Water resource planning under climate uncertainty in London. Atkins Report (Reference 5103993/73/DG/035) for the Adaptation Sub-Committee and Thames Water. Atkins, Epsom

Department for Communities and Local Government: London (2009) Multi-criteria analysis: a manual. London

Dessai S, van der Sluijs J (2011) Modelling climate change impacts for adaptation assessments. In: Christie M, Cliffe A, Dawid P, Senn A (eds) Simplicity, complexity and modelling. Wiley, Chichester, pp 83-102

Dessai S, Hulme M, Lempert R, Pielke R Jr (2009) Climate prediction: a limit to adaptation? In: Adger WN, Lorenzoni I, O'Brien K (eds) Adapting to climate change: thresholds, values, governance. Cambridge University Press, Cambridge, pp 64-78

Environment Agency (2008) Water resources planning guidelines. http://environment-agency.gov.uk/business/ sectors/39687.aspx. Accessed 12 January 2010

Environment Agency (2001) Water resources for the future: a strategy for England and Wales. Environment Agency, Bristol

Environment Agency (2004) Maintaining water supplies. Environment Agency, Bristol

Hall JW, Fu G, Lawry J (2007) Imprecise probabilities of climate change: aggregation of fuzzy scenarios and model uncertainties. Clim Chang 81(3-4):265-281

Hall JW, Watts G, Keil M, de Vial L, Street R, Conlan K, O’Connell PE, Beven KJ, Kilsby CG (2011) Towards risk-based water resources planning in England and Wales under a changing climate. Water Env J. doi:10.1111/j.1747-6593.2011.00271.x

Hine D, Hall JW (2010) Information gap analysis of flood model uncertainties and regional frequency analysis. Water Resour Res 46:W01514. doi:10.1029/2008WR007620

Hipel KW, Ben-Haim Y (1999) Information-Gap modeling in water resources management. IEEE Trans Syst Man Cybern Part C Appl Rev 29(4):506-517

HM Government (2012) UK climate change risk assessment: government report. TSO, London

HM Treasury (2011) The green book, appraisal and evaluation in central government. TSO, London

Janssen R (2001) On the use of multi-criteria analysis in environmental impact assessment in the Netherlands. J Multi-Criteria Decis Anal 10:101-109

Jones RN (2000) Managing uncertainty in climate change projections-issues for impact assessment. Clim Chang 45(3-4):403-419

Kiang JE, Olsen JR, Waskomm RM (2011) Introduction to the featured collection on "nonstationarity, hydrologic frequency analysis, and water management". J Am Water Res Assoc (JAWRA) 47(3):433435. doi:10.1111/j.1752-1688.2011.00551.x

Kiker GA, Bridges TS, Varghese A, Seager TP, Linkov I (2005) Application of multicriteria decision analysis in environmental decision making. Integr Environ Assess Manag 1:95-108. doi:10.1897/ IEAM_2004a-015.1

Kriegler E, Hall JW, Held H, Dawson RJ, Schellnhuber HJ (2009) Imprecise probability assessment of tipping points in the climate system. Proc Natl Acad Sci USA 106(13):5041-5046

Lempert RJ, Groves DG (2010) Identifying and evaluating robust adaptive policy responses to climate change for water management agencies in the American west. Tech Forcasting Soc Chang 77:960-974

Lempert RJ, Schlesinger ME (2000) Robust strategies for abating climate change. Clim Chang 45(3-4):387-401

Lopez A, Tebaldi C, New M, Stainforth D, Allen M, Kettleborough J (2006) Two approaches to quantifying uncertainty in climate change. J Clim 19:4785-4796

Lopez A, Fung F, New M, Watts G, Weston A, Wilby RL (2009) From climate model ensembles to climate change impacts and adaptation: a case study of water resource management in the southwest of England. Water Resour Res 45:W08419. doi:10.1029/2008WR007499

Makropoulous CK et al (2008) Decision support for sustainable option selection in integrated urban water management. Environ Model Softw 23(12):1448-1460

Manning LJ, Hall JW, Fowler HJ, Kilsby CG, Tebaldi C (2009) Using probabilistic climate change information from a multimodel ensemble for water resources assessment. Water Resour Res 45:W11411. doi:10.1029/2007WR006674

Matrosov E, Harou JJ, Loucks DP (2011) Computationally efficient open-source water resource system simulation model: IRAS-2010 - application to London and the Thames Basin. J Environ Model Softw. doi:10.1016/j.envsoft.2011.07.013 
Mayer A, Muñoz-Hernandez A (2009) Integrated water resources optimization models: an assessment of a multidisciplinary tool for sustainable water resources management strategies. Geogr Compass 3(3):11761195. doi:10.1111/j.1749-8198.2009.00239.x

McCarthy MA, Lindenmayer DB (2007) Info-Gap decision theory for assessing the management of catchments for timber production and urban water supply. Environ Manag 39:553-562

McIntyre N, Lees M, Wheater H, Onof C, Connorton B (2003) Evaluation and visualization of risk to water resources. Proc Inst Civil Eng Water Marit Eng 156(1):1-11

Milly PCD, Betancourt J et al (2008) Climate change - stationarity is dead: whither water management? Science 319(5863):573-574

Murphy JM, Sexton DMH et al (2009) UK climate projections science report: climate change projections. Met Office Hadley Centre, Exeter

National Research Council (2009) Informing decisions in a changing climate. Washington, DC

NERA (2002) The economics of balancing supply and demand-main report. London

New M, Lopez A, Dessai S, Wilby R (2007) Challenges in using probabilistic climate change information for impact assessments: an example from the water sector. Philos Trans R Soc 365:2117-2131

Ranger N, Millner A, Dietz S, Fankhauser S, Lopez A, Ruta G (2010) Adaptation in the UK: a decisionmaking process - policy brief. Grantham Research Institute on Climate Change and the Environment, London

Regan HM, Ben-Haim Y, Langford B, Wilson WG, Lundberg P, Andelman SJ, Burgman MA (2005) Robust decision-making under severe uncertainty for conservation management. Ecol Appl 15(4):1471-1477

South West Water (2009) Water resources plan 2010-2035. http://www.southwestwater.co.uk/index.cfm? articleid=1556. Accessed: 12 January 2010

South West Water (2010) Charges 2010/2011. http://www.southwestwater.co.uk/media/pdf/e/5/ FinalCS10111 webV0.1.pdf. Accessed: 26 September 2011

Steele KS, Carmel Y, Cross J, Wilcox C (2009) Uses and misuses of multicriteria decision analysis (MCDA) in environmental decision making. Risk Anal 29(1):26-33, ISSN 1539-6924

UKWIR (2009) Assessment of the significance to water resource management plans of the UK Climate Projections 2009. (09/CL/04/11)

US Climate Change Science Program (2009) Final report of synthesis and assessment product 5.2. http:// www.climatescience.gov/Library/sap/default.htm. Accessed: 12 September 2010

US Army Corps of Engineers Institute for Water Resources (2010) IWR Planning Suite MCDA Module User's Guide. http://www.pmcl.com/iwrplan/MCDAUsersGuideSep10.pdf. Accessed: 20 April 2012

Ward S (2010) Rainwater harvesting in the UK: a strategic framework to enable transition from novel to mainstream. http://hdl.handle.net/10036/106575. Accessed: 10 July 2011

Wilby R (2010) Evaluating climate model outputs for hydrological applications—opinion. Hydrol Sci J 55 (7):1090-1093

Wilby RL, Dessai S (2010) Robust adaptation to climate change. Weather 65(7):180-185

Wilby RL, Harris I (2006) A framework for assessing uncertainties in climate change impacts: low-flow scenarios for the River Thames UK. Water Resour Res 42:W02419. doi:10.1029/2005WR004065 